\title{
Cultura impresa e identidad nacional en El Salvador a fines del siglo XIX. Una perspectiva comparativa*
}

\author{
por Iván Molina
}

\begin{abstract}
This article is inspired on E. Bradford Burns' study about the Salvadorean "intellectual infrastructure" published in 1985. I argue that such "intellectual infrastructure" was more limited than Burns believed at first. This conclusion is based on a systematic comparison of the Salvadorean printed culture with the Nicaraguan and Costa Rican one, considering also the levels of popular literacy, the role played by the intellectual circles, the cultural policies developed by the state in such countries, and the different processes of the "invention" of nation.
\end{abstract}

La configuración de "una infraestructura intelectual seglar" en El Salvador, a finales del siglo XIX, fue el eje de un artículo ya clásico del investigador estadounidense, E. Bradford Burns, publicado en $1985 \mathrm{y}$ según el cual

“... el café proporcionaba el financiamiento suficiente para ... [esa infraestructura, IM] y la riqueza dejaba más tiempo libre para las búsquedas intelectuales y culturales, de igual forma que el floreciente comercio de exportación conectaba a El Salvador cada vez más con las naciones del Atlántico Norte, facilitando así la exposición de los salvadoreños privilegiados a las nuevas ideas."

La transformación cultural que supuso el creciente contacto con los países europeos (especialmente con Francia e Inglaterra) dejó su im-

* La investigación que sirvió de base para este artículo se efectuó en el Centro de Investigación en Identidad y Cultura Latinoamericanas (CIICLA) y fue financiada por la Universidad de Costa Rica.

${ }^{1}$ E. Bradford Burns, "The Intellectual Infrastructure of Modernization in El Salvador, 1870-1900”: The Americas XLI, 3 (Washington D. C. 1985), pp. 57-82, aquí: p. 59. La cita es de la traducción española: "La infraestructura intelectual de la modernización en El Salvador, 1870-1900": Luis René Cáceres (ed.), Lecturas de historia de Centroamérica (San José 1989), pp. 565-591, aquí: p. 566. 
pronta en esa "sólida infraestructura intelectual", la cual, de acuerdo con Burns,

“... consistía primordialmente de una universidad, una biblioteca nacional, academias y publicaciones, todas orientadas hacia Europa, [y] se entrelazaba con las estructuras políticas, reforzándolas, aunque al mismo tiempo sacando fuerza de ellas. Los intelectuales entusiastamente abrazaron la modernización seleccionada por las élites políticas y económicas. En el proceso, repudiaron el pasado indoibérico de la nación por considerarlo atrasado. Ignoraron la realidad de que la modernización seleccionada sólo beneficiaba a una pequeña minoría ..."²

Los procesos anteriores, sin embargo, no fueron exclusivos de El Salvador, ya que otros países latinoamericanos vivieron experiencias similares, como lo evidencian las investigaciones efectuadas, en los últimos quince años, especialmente para los casos de México, Brasil y Argentina. ${ }^{3}$ El propósito de este artículo es examinar los planteamientos de Burns desde una perspectiva más amplia, que permita visualizar la especificidad del caso salvadoreño en el contexto centroamericano. La estrategia metodológica escogida consistió en comparar la cultura impresa de este último país (una de las bases de su "infraestructura intelectual") con la que se configuró en Costa Rica y Nicaragua en las dos últimas décadas del siglo XIX, ${ }^{4}$ dos sociedades cuyas profundas diferencias empezaron a ser destacadas desde antes de 1850 .

\section{LIBROS, FOLLETOS Y CULTURA URBANA}

La comparación de las obras publicadas en los tres países en el período especificado se basa en el Índice bibliográfico de Costa Rica, publicado por Luis Dobles Segreda entre 1927 y 1936; en la Bibliografía nacional nicaragüense, preparada por la Latin American Bi-

${ }^{2}$ Burns, "The Intellectual Infrastructure" (nota 1), p. 81; "La infraestructura intelectual" (nota 1), p. 583.

${ }^{3}$ Véase, entre otras obras: Jeffrey D. Needell, A Tropical Belle Epoque: Elite Culture and Society in Turn of the Century Rio de Janeiro (Cambridge 1987); Teresa A. Meade, "Civilizing" Rio: Reform and Resistance in a Brazilian City, 1889-1930 (Pennsylvania 1997); Eduardo A. Zimmermann, Los liberales reformistas: la cuestión social en la Argentina, 1890-1916 (Buenos Aires 1995); Michael Johns, The City of Mexico in the Age of Díaz (Austin 1997).

${ }^{4}$ La comparación es más sistemática con Costa Rica que con Nicaragua, dado que la información disponible para este último país es más limitada. 
bliographic Foundation y el Ministerio de Cultura de Nicaragua en la década de 1980; y en la "Lista preliminar de la Bibliografía Salvadoreña", elaborada por Mariano García Villas en 1952 con base en los materiales existentes en la Biblioteca Nacional. ${ }^{5}$ Esta última recopilación no es tan exhaustiva como las dos precedentes, pero es una fuente muy valiosa para analizar los libros y folletos publicados en El Salvador durante el siglo XIX.

El Cuadro 1 ofrece la distribución departamental de todas las obras e imprentas que fueron localizadas entre 1880 y 1899; según esta información, San Salvador concentró el 92,6 por ciento de unas y el 53,4 por ciento de las otras. ${ }^{6}$ La capital salvadoreña, en cuanto a los talleres de impresión, se ubicaba en una posición intermedia entre Managua y San José. La primera de estas ciudades concentró, en el período señalado, el 32,4 por ciento del total de tipografías de Nicaragua, en cambio, esa proporción ascendió a 77,8 por ciento en el casco urbano josefino, ${ }^{7}$ un indicador de la temprana centralización espacial que alcanzó la actividad tipográfica en Costa Rica.

${ }^{5}$ Luis Dobles Segreda, Índice bibliográfico de Costa Rica (San José 1927-1936 y 1968); Latin American Bibliographic Foundation/Ministerio de Cultura de Nicaragua, Bibliografía nacional nicaragüense, 1800-1978 (Redlands 1986); Mariano García Villas, "Lista preliminar de la Bibliografía Salvadoreña de las obras existentes en la Biblioteca Nacional" (San Salvador 1952, manuscrito inédito). Los datos costarricenses y nicaragüenses se encuentran resumidos en: Iván Molina, "Impresiones de fin de siglo. La expansión de la cultura impresa en Costa Rica y Nicaragua (1880-1914)": Iván Molina/Patricia Fumero, La sonora libertad del viento. Sociedad y cultura en Costa Rica y Nicaragua (1821-1914) (México 1997), pp. 135-156, aquí: pp. 139 y 142-143.

${ }^{6}$ Para una crónica de las principales imprentas de San Salvador entre 1880 y 1925 , véase: Apolonio Monches, "La tipografía en El Salvador": Revista del Ateneo de El Salvador XIII, 107 y 108 (San Salvador 1926), pp. 4195-4200. 
CUADRO 1

IMPRENTAS Y NÚMERO DE LIBROS Y FOLLETOS PUBLICADOS EN El SALVADOR (1880-1899)

\begin{tabular}{lrrcccr}
\hline Lugar & Imprentas & $\begin{array}{c}\text { Libros y } \\
\text { folletos }\end{array}$ & $\begin{array}{c}\text { Libros y } \\
\text { folletos }\end{array}$ & $\begin{array}{c}\text { No. de } \\
\text { imprentas }\end{array}$ & $\begin{array}{c}\text { No. páginas de } \\
\text { libros y folletos }\end{array}$ & No. \\
\hline San Salvador & 24 & 534 & $1-4$ & 27 & $1-9$ & 52 \\
Santa Ana & 8 & 21 & $5-9$ & 0 & $10-24$ & 284 \\
San Miguel & 5 & 4 & $10-24$ & 4 & $25-49$ & 93 \\
Sonsonate & 4 & 6 & $25-49$ & 2 & $50-99$ & 51 \\
Cuscatlán & 1 & 1 & $50-99$ & 2 & $100-199$ & 44 \\
San Vicente & 1 & 0 & $100+$ & 1 & $200-499$ & 40 \\
La Libertad & 1 & 9 & $\ldots$ & $\ldots$ & 500 y más & 4 \\
La Paz & 1 & 2 & $\ldots$ & $\ldots$ & desconocido & 9 \\
\hline Total & 45 & 577 & Total & 36 & Total & 577 \\
\hline
\end{tabular}

* De las 45 imprentas localizadas, nueve parece que no publicaron libros ni folletos. Fuente: García Villas, "Lista preliminar de la Bibliografía Salvadoreña" (nota 5).

La experiencia salvadoreña, en cuanto a la distribución geográfica de libros y folletos, estuvo más cercana, sin embargo, a la de Costa Rica que a la de Nicaragua. La proporción de obras publicadas en Managua, en los veinte años posteriores a 1880 , fue de apenas un 69,8 por ciento del total nacional, una cifra muy inferior al 98,1 por ciento que concentró San José. ${ }^{8}$ La producción libresca, por tanto, tuvo escasa importancia en la cultura (y en las identidades) de las jerarquías departamentales de El Salvador, pese a que en este país no existía la fuerte desigualdad demográfica entre la capital y las otras ciudades que caracterizaba al universo urbano costarricense.

La estructura urbana de El Salvador finisecular se distinguía, en efecto, porque la capital, con sus 30.000 vecinos, no era la ciudad más poblada del país, una posición que le correspondía a Santa Ana (33.000 personas), epicentro del cultivo cafetalero. Los datos censales de 1892 revelan, además, que de un total de 703.500 habitantes, únicamente 173.500 (un 24,5 por ciento) vivían en las cabeceras departamentales. El peso demográfico de los capitalinos era, en consecuencia,

\footnotetext{
7 Molina, "Impresiones de fin de siglo" (nota 5), p. 143.

8 Ibidem, p. 139.
} 
bastante limitado: un 4,3 por ciento de todos los salvadoreños, y un 17,3 por ciento de la población citadina. ${ }^{9}$ La situación de San Salvador se visualiza mejor al compararla con la de San José.

Los procesos de colonización agrícola campesina, que caracterizaron a la Costa Rica del siglo XIX, acentuaron la ruralización del país, ${ }^{10}$ y explican que, en 1892, solo un 16,3 por ciento de los costarricenses viviera en las cabeceras provinciales. Los asentados en la capital representaban, sin embargo, el 8 por ciento del total de almas y el 48,8 por ciento de quienes residían en ciudades. ${ }^{11} \mathrm{El}$ cosmopolitismo josefino y sus modelos culturales europeizados fueron, por tanto, una experiencia potencialmente compartida por una proporción mayor de todos los pobladores, y por casi la mitad de los citadinos. El casco de San José tuvo en la sociedad y la cultura nacional y urbana una centralidad de la que no gozó su contraparte salvadoreña.

El caso de El Salvador se asemejaba más al de la Nicaragua de 1920: en ese año, los vecinos de las cabeceras departamentales suponían un 19 por ciento del total de almas, y los que vivían en Managua, constituían un 4,4 por ciento de todos los nicaragüenses, y un 22,6 por ciento de los asentados en ciudades. ${ }^{12}$ La principal diferencia entre tales países consistía en que, en la patria de Darío, ciudades como León y Granada eran importantes centros de la cultura impresa (un 26 por ciento de todos los libros y folletos publicados entre 1880 y 1899$) ;{ }^{13}$ en contraste, en la tierra de Masferrer la producción libresca quedó circunscrita a una capital cuyo peso era muy limitado en el conjunto de la población urbana.

9 International Bureau of American Republics, Handbook of Salvador (Washington 1892), p. 9. La expansión de la ciudad de San Salvador se analiza en: Mario Lungo Uclés/Sonia Baires, "Población y economía en la consolidación de la capital salvadoreña 1880-1930": Rodrigo Fernández Vásquez/Mario Lungo Uclés (eds.), La estructuración de las capitales centroamericanas (San José 1988), pp. 133-159, aquí: 135-155.

${ }_{10}$ Mario Samper, Generations of Settlers: Rural Households and Markets on the Costa Rican Frontier, 1850-1935 (Boulder 1990).

${ }_{11}$ Censo general de la República de Costa Rica, 18 de febrero de 1892 (San José 1893), pp. xix-lii.

12 República de Nicaragua. Censo general de 1920 (Managua 1920), pp. 1-10.

13 Molina, "Impresiones de fin de siglo" (nota 5), p. 139. 


\section{PERIÓDICOS, REVISTAS Y ALFABETIZACIÓN POPULAR}

El examen de periódicos y revistas se basa en los catálogos respectivos elaborados por la Hemeroteca Nacional para Nicaragua, por Adolfo Blen y Francisco María Núñez para Costa Rica, y por Italo López Vallecillos para El Salvador. ${ }^{14}$ El más incompleto de todos es este último, ya que, aparte de estar afectado por un subregistro significativo, de las publicaciones periódicas que sí incluye, suele ofrecer una información fragmentaria. El lugar de impresión y la periodicidad son dos datos muy valiosos que, con frecuencia, están ausentes, y solo por excepción, se especifica cuál fue el taller tipográfico encargado del tiraje, debilidades todas visibles en el Cuadro 2.

La base de datos disponible de periódicos y revistas está más completa para Nicaragua (140 títulos), que para Costa Rica (97 títulos) y El Salvador (74 títulos), un factor que dificulta comparar los tres casos; pero las diferencias detectadas, una vez que son consideradas en conjunto, permiten identificar varias tendencias básicas. La primera se vincula con el desigual peso que tuvo un factor clave en la "invención de la nación": la prensa diaria. ${ }^{15}$ Los diarios representaron el 25,7 por ciento de todas las publicaciones periódicas nicaragüenses, el 22,7 por ciento de las costarricenses, y el 17,6 de las salvadoreñas, localizadas para el período $1880-1899 .{ }^{16}$

${ }^{14}$ Adolfo Blen, "El periodismo en Costa Rica" (San José, manuscrito inédito); Francisco María Núñez, La evolución del periodismo en Costa Rica (San José 1921); ídem, Periódicos y periodistas (San José 1980); Hemeroteca Nacional, Catálogo de periódicos y revistas de Nicaragua (1830-1930) (Managua 1992); Italo López Vallecillos, El periodismo en El Salvador (San Salvador 1987). La información de Costa Rica y Nicaragua está resumida en: Molina, "Impresiones de fin de siglo" (nota 5), pp. 138, 141 y 143.

15 Benedict Anderson, Imagined Communities: Reflections on the Origen and Spread of Nationalism, (2da. ed., Londres 1991), pp. 33-36.

16 Molina, "Impresiones de fin de siglo" (nota 5), p. 143. 
CUADRO 2

Periódicos y REVISTAS PUblicados EN El SALVAdOR (1880-1899)

\begin{tabular}{lccccc}
\hline Lugar & $\begin{array}{c}\text { Periódicos } \\
\text { y revistas }\end{array}$ & Periodicidad & Periódicos y & $\begin{array}{c}\text { Período } \\
\text { revistas }\end{array}$ & $\begin{array}{c}\text { Periódicos* } \\
\text { y revistas }\end{array}$ \\
\hline San Salvador & 28 & Diario & 13 & $1880-84$ & 32 \\
Santa Ana & 8 & Semanal & 13 & $1885-89$ & 15 \\
San Miguel & 1 & Quincenal & 7 & $1890-94$ & 13 \\
San Vicente & 1 & Mensual & 5 & $1895-99$ & 14 \\
La Libertad & 1 & Desconocido & 36 & $\ldots$ & $\ldots$ \\
Desconocido & 35 & $\ldots$ & $\ldots$ & $\ldots$ & $\ldots$ \\
\hline Total & 74 & Total & 74 & Total & 74 \\
\hline
\end{tabular}

De los 32 periódicos y revistas del lapso 1880-1884, por lo menos 7 existían desde antes de 1880. Fuente: López Vallecillos, El periodismo en El Salvador (nota 14).

El segundo contraste significativo está asociado con el origen geográfico de la producción tipográfica y la posición ocupada por la capital. San Salvador concentró el 37,8 por ciento de los 74 periódicos y revistas catalogados para los años 1880-1899, y un 71,8 por ciento de todos los materiales de ese tipo cuyo lugar de impresión fue posible determinar. La experiencia salvadoreña, en este sentido, parece que estuvo más próxima a la de Costa Rica que a la de Nicaragua. La proporción de publicaciones periódicas impresas en San José y Managua ascendió a 87,6 y a 36,8 por ciento de todas las que fueron localizadas, en esos países, para las dos últimas décadas del siglo XIX. ${ }^{17}$

El bajo porcentaje de periódicos y revistas que concentró la capital nicaragüense se explica por la importancia de la prensa departamental, en especial la de León y Granada. Las jerarquías políticas e intelectuales de esas ciudades, fuertemente divididas en lo ideológico (liberales y conservadores), ${ }^{18}$ encontraron en la cultura impresa un instru-

17 Ibidem, p. 138.

${ }^{18}$ E. Bradford Burns, Patriarch and Folk: The Emergence of Nicaragua, 1798-1850 (Cambridge, Mass. 1991); Frances Kinloch, Nicaragua: identidad y cultura politica (1821-1858) (Managua 2000).

19 Patricia Fumero, "De la iniciativa individual a la cultura oficial: el caso del General José Dolores Estrada en la Nicaragua de la década de 1870": Molina/Fumero, La sonora libertad del viento (nota 5), pp. 13-41; Miguel Angel Herrera, "Nacionalismo e historiografía sobre la guerra del 56. Nicaragua, 1850-1889": Revista de Historia 2 (Managua 1992-1993), pp. 27-39. 
mento para defender sus intereses, reforzar sus identidades y consolidar sus diferencias en la incipiente esfera pública que se configuró al finalizar el siglo XIX. El Salvador, pese al rezago demográfico capitalino, parece haberse exceptuado de ese localismo cultural que complicó tanto los esfuerzos oficiales por "nacionalizar" a Nicaragua. ${ }^{19}$

La última diferencia que vale la pena destacar, a la luz del Cuadro 2, es la distribución por quinquenios de los periódicos y revistas. Los datos de El Salvador sugieren que tal proceso se estancó, una impresión que es reforzada al considerar la información procedente de los países vecinos. La prensa periódica, en Nicaragua, pasó de 30 títulos entre 1880 y 1884 , a 38 entre 1885 y 1889 , bajó a 26 entre 1890 y 1894, y alcanzó un máximo de 46 entre 1895 y 1899. La tendencia costarricense, falta de esas irregularidades, revela un crecimiento sostenido: de 5 publicaciones entre 1885 y 1889, a 24 en el quinquenio siguiente, a 30 entre 1890 y 1894 , y a 38 entre 1895 y 1899.

El estancamiento de la prensa en El Salvador podría ser, sin duda, solo aparente, ya que es posible considerar las cifras quinquenales salvadoreñas como un indicador de que los periódicos y revistas eran, simplemente, más estables en ese país que en Nicaragua y Costa Rica. La falta de datos sistemáticos sobre la duración de tales publicaciones no permite resolver todavía esta cuestión; pero es útil considerar el comportamiento de la producción de libros y folletos. El total respectivo bajó de 198 a 158 en los dos últimos lustros del siglo XIX, una caída menos aguda que la de Nicaragua (de 150 a 92 títulos); en contraste, en Costa Rica el tiraje de obras se elevó de 75 entre 1880 y 1884, a 94 entre 1885 y 1889 , a 144 entre 1890 y 1894 y a 159 en el siguiente quinquenio.

La cultura impresa en El Salvador, por tanto, parece haber alcanzado un techo en el decenio de 1890. La base de esta limitación fue muy probablemente un elevado analfabetismo popular, el cual jugó en contra de la ampliación y diversificación de las audiencias de lectores y, en consecuencia, del mercado cultural mismo. Los datos de Costa Rica y Nicaragua ofrecen un útil marco comparativo: de los varones urbanos costarricenses nacidos entre 1886 y 1895 (los cuales alcanzaron

20 Segundo censo de población, junio 13 de 1950 (San Salvador 1954), p. 298; Censo de población de Costa Rica, 22 de mayo de 1950 (2da. edición, San José 1975), pp. 267 y 269; Censo general de población de la República de Nicaragua mayo de 1950 (Managua 1954), p. 188. 
los veinte años entre 1906 y 1915), un 84,3 por ciento se alfabetizó; y de las mujeres de esa cohorte, un 82,5 por ciento aprendió a leer y escribir. Las proporciones nicaragüenses ascendieron a 66,5 y 63,9 por ciento, y las salvadoreñas fueron aún más bajas: 63,9 y 46,4 por ciento, respectivamente.

Las cifras del campo revelan diferencias todavía mayores: de los varones y las mujeres rurales que vinieron al mundo en Costa Rica entre 1886 y 1895 , un 66,9 y un 46,4 por ciento se alfabetizaron; en Nicaragua, tales proporciones fueron de 27,1 y 16,5 por ciento, y en la patria de Masferrer, de 25,6 y 11,2 por ciento. ${ }^{20}$ La expansión educativa salvadoreña, cuyas contradicciones Burns destacó en su artículo de $1985,{ }^{21}$ fue una experiencia social (y étnicamente) muy limitada, en especial en el agro. ${ }^{22}$ El universo urbano tenía mejores índices sin duda, pero aun así, casi la mitad del total de varones y mujeres que nacieron en las ciudades de El Salvador en el decenio ya especificado, permanecieron sin alfabetizarse, a juzgar por los datos del censo de 1950.

Los salvadoreños que sabían leer y escribir superaban, en cuanto a cifras absolutas, a los costarricenses de la misma condición (185.000 y 76.000 personas según datos del período $1887-1892) .{ }^{23}$ La cultura impresa de El Salvador, sin embargo, estaba dirigida a una audiencia de lectores poco diferenciada social y culturalmente, compuesta en esencia por los sectores medios y acaudalados de las ciudades. La creciente alfabetización popular costarricense, en contraste, fue la base de una ampliación y diversificación decisivas del mercado cultural urbano y rural. La prensa artesano-obrera que debutó en Costa Rica a partir de la década de 1880 y el consumo cada vez mayor de cartillas de

${ }^{21}$ Burns, "The Intellectual Infrastructure" (nota 1), pp. 63-66. Curiosamente, Burns no utilizó los censos para precisar los niveles de alfabetización.

${ }^{22}$ El censo salvadoreño de 1950 no permite analizar la alfabetización por grupos étnicos, pero es verosímil que los indígenas, en su mayoría asentados en el campo, destacaran entre los analfabetas rurales.

${ }^{23}$ Censo general de la República de Costa Rica (nota 11), pp. cviii-cix. Carlos Gregorio López Bernal, "El proyecto liberal de nación en El Salvador (1876-1932)" (Tesis de Maestría en Historia, Universidad de Costa Rica, 1998), p. 67. Lungo Uclés/Baires, "Población y economía" (nota 9), p. 137. La cifra de alfabetas para El Salvador puede estar sobrevalorada, como mínimo, en un 10 por ciento, a juzgar por los datos del censo salvadoreño de 1950 relativos a los nacidos entre 1885 y 1896. Véase: Segundo censo de población (nota 20), p. 298. 
divulgación científica entre los campesinos fueron, entre otros, dos de los indicadores principales del proceso señalado. ${ }^{24}$

\section{IMPRENTAS PRIVADAS Y ESTATALES}

Los cuadros 1 y 2 permiten detectar otras limitaciones adicionales de la "infraestructura intelectual" analizada por Burns, vinculadas con la actividad propiamente editorial: aunque para el El Salvador fue posible localizar, entre 1880 y 1899 , más tipografías productoras de libros y folletos (36) que para Nicaragua (32) y Costa Rica (22), el 36,4 por ciento de los talleres costarricenses y el 28 por ciento de los nicaragüenses imprimieron cinco o más títulos. ${ }^{25}$ La proporción de locales salvadoreños ubicados en esa categoría ascendió solo a un 25 por ciento, dato que destaca el carácter esporádico que tenía el tiraje de obras en el universo tipográfico de ese país centroamericano.

Las 577 obras y opúsculos localizados para El Salvador, en el período especificado, superan de nuevo, en términos absolutos, los totales correspondientes a Nicaragua (388) y Costa Rica (472). ${ }^{26}$ La ponderación de esas cifras con los datos poblacionales, sin embargo, ofrece un resultado muy distinto: entre 1880 y 1899 , el promedio de personas por título impreso ascendió a 1.219 en la patria de Masferrer, a 928 en la de Darío y a 515 en la de Joaquín García Monge (el editor del Repertorio Americano). ${ }^{27}$ La producción per cápita de libros y folletos, en el caso costarricense, casi duplicaba la nicaragüense y superaba en 2,4 veces a la salvadoreña.

La extensión de los títulos publicados es útil para investigar, desde una perspectiva más cualitativa, la cultura impresa. Los cuadros 1 y 2

${ }^{24}$ Mario Oliva, Artesanos y obreros costarricenses 1880-1914 (San José 1985), pp. 101-102; Iván Molina, El que quiera divertirse. Libros y sociedad en Costa Rica (1750-1914) (San José 1995), pp. 131-166; Carlos Naranjo, "La modernización de la caficultura 1890-1950" (Tesis de Maestría en Historia, Universidad de Costa Rica, 1997).

${ }^{25}$ Molina, "Impresiones de fin de siglo" (nota 5), p. 142.

26 Ibidem.

${ }^{27}$ El cálculo se hizo con base en la población de Costa Rica y El Salvador en 1892, y la de Nicaragua en 1890. Censo general de la República de Costa Rica (nota 11), pp. xix-lii. International Bureau of American Republics, Handbook of Salvador (nota 9), p. 9. International Bureau of American Republics, Handbook of Nicaragua, (Washington 1898), p. 8. 
revelan que un 75,5 por ciento de todos los opúsculos y libros que circularon en El Salvador entre 1880 y 1899 tenía menos de 50 páginas. La producción nicaragüense que se ubicó en ese nivel ascendió a 68,3 por ciento, en tanto que la costarricense fue de solo un 40,6 por ciento. El carácter visiblemente folletinesco de los textos salvadoreños se detecta mejor cuando se considera que únicamente un 15,5 por ciento alcanzaba las 100 páginas o más (en Nicaragua, tal cifra ascendió 17,3 por ciento); en contraste, la proporción de tales obras en Costa Rica se elevó a 37,9 por ciento. ${ }^{28}$

La tipografía del Estado fue otro factor de diferenciación, ya que entre 1880 y 1899 concentró el grueso de la producción de libros y folletos en Costa Rica (un 76,5 por ciento), mientras que en Nicaragua (un 50,5 por ciento) y en El Salvador (49,9 por ciento) esa cifra fue más reducida. El limitado papel del taller estatal en el país de Masferrer se vislumbra mejor al examinar el peso de las publicaciones oficiales. El 42,8 por ciento de todas las obras y opúsculos salvadoreños que circularon en los veinte años finales del siglo XIX fueron de esta índole, una proporción muy inferior a la nicaragüense (60,8 por ciento) y a la costarricense (63,3 por ciento). ${ }^{29}$ La magnitud de esta última cifra es un indicador del interés de los gobiernos asentados en San José por tener una amplia presencia en la esfera pública de la época.

El círculo de políticos e intelectuales salvadoreños que controlaba el Poder Ejecutivo, a diferencia de su contraparte costarricense, careció de una perspectiva clara acerca del papel que la tipografía estatal debía jugar en la política cultural y, en particular, en los esfuerzos oficiales por secularizar la sociedad y "civilizar" a las culturas populares. ${ }^{30}$ La administración de Rafael Zaldívar (1876-1885) llegó al extremo de que eliminó el taller del Estado, al vendérselo a Fransisco Sagrini. La ausencia de un establecimiento de este tipo se prolongó hasta el ascenso al poder de Francisco Menéndez (1885-1890), cuyo

${ }^{28}$ Molina, "Impresiones de fin de siglo" (nota 5), p. 143.

29 Ibidem, p. 142. No todos los libros y folletos impresos en los talleres estatales califican como oficiales, razón por la cual su proporción es inferior al total de textos que circularon con el sello de esas tipografías.

30 Para una discusión más amplia a nivel latinoamericano, véase: Meade, "Civilizing" Rio (nota 3), pp. 17-44; William E. French, "Prostitutes and Guardian Angels: Women, Work and the Family in Porfirian Mexico": Hispanic American Historical Review 72, 4 (Durham 1992), pp. 529-553. 
gobierno volvió a comprar el equipo y abrió de nuevo la imprenta nacional. $^{31}$

Los avatares del taller estatal en El Salvador explican que, entre 1880 y 1899 , el 34,8 por ciento de los textos oficiales en ese país fueran tirados en imprentas privadas, proporción más alta que la nicaragüense (21,2 por ciento) y, sobre todo, que la costarricense $(0,4$ por ciento). El avance que experimentó la alfabetización popular en Costa Rica fue acompañado por una política cultural, diseñada y ejecutada por el Estado, cuyo fin era difundir entre campesinos, artesanos y otros trabajadores la ideología del progreso, en su sentido capitalista y positivista. ${ }^{32}$ El papel estratégico que la tipografía nacional debía cumplir en ese proceso se patentizó en una inversión creciente en equipo, la cual convirtió a dicho establecimiento en uno de los principales de Centroamérica. ${ }^{33}$

\section{Publicaciones oficiales E institucionales}

La temática de los libros y folletos que circularon en El Salvador, Nicaragua y Costa Rica entre 1880 y 1899 se compara en el Cuadro 3, el cual los clasifica según su origen. Los oficiales son los textos preparados por orden del Estado e impresos en su propio taller (compilaciones de leyes y decretos, manuales escolares, cartillas populares, memorias y otros similares) o en tipografías privadas. Los de carácter institucional, que usualmente consistían en estatutos, prospectos e informes, corresponden a organizaciones no estatales, como la Iglesia católica, clubes, asociaciones, sociedades y centros escolares, o a entidades financiadas con fondos públicos, pero administradas descen-

\footnotetext{
${ }^{31}$ López Vallecillos, El periodismo en El Salvador (nota 14), pp. 59-60.

32 Molina, El que quiera divertirse (nota 24), pp. 131-166. Acerca del positivismo, véase: Charles A. Hale, "Political and Social Ideas in Latin American, 1870-1930": Leslie Bethell (ed.), The Cambridge History of Latin America (Cambridge 1986), t. IV, pp. 367-441, aquí: pp. 382-414.

${ }_{33}$ Molina, El que quiera divertirse (nota 24), pp. 146-148. Patricia Vega, "Entre la oscuridad y la luz (El trabajo en la Imprenta Nacional 1868-1885)": Patricia Vega/Carolina Carazo (eds.), Comunicación y cultura. Una perspectiva interdisciplinaria (San José 1998), pp. 41-63, aquí: 58-62. Gabriela Villalobos, “'Otro modo de ser...' Las transformaciones en el mundo laboral de las imprentas josefinas, 1880-1904”: Iván Molina/Francisco Enríquez (eds.), Fin de siglo XIX e identidad nacional en México y Centroamérica (Alajuela 2000), pp. 27-56.
} 
tralizadamente por juntas de notables locales (hospitales y asilos). Los particulares, a su vez, eran las obras y opúsculos elaborados por uno o varios individuos, a título personal y publicados privadamente.

La proporción de textos oficiales, como ya se indicó, fue más baja en El Salvador que en Nicaragua y Costa Rica. Lo contrario ocurrió con las publicaciones de carácter institucional, que supusieron 17,2 por ciento en el primer país, 10,1 por ciento en el segundo y 3,6 por ciento en el tercero. Este contraste no se explica por el número de organizaciones no estatales y entidades descentralizadas, ya que el total de las costarricenses superaba al de las nicaragüenses y al de las salvadoreñas (véase el Cuadro 4). La ponderación demográfica de tales cifras acentuaría la diferencia indicada, dado que la población de la tierra de García Monge era inferior a la de las patrias de Masferrer y Darío.

El peso diferenciado de los textos institucionales obedecía a que, en El Salvador, y en menor grado en Nicaragua, esas organizaciones y entidades solían publicar sus estatutos, reglamentos y memorias en forma de folleto, en tanto que, en Costa Rica, lo usual era que tales materiales fueran impresos en periódicos y revistas. La razón de esta divergencia no es clara, aunque podría estar vinculada, en parte, con el tipo de asociaciones fundadas en las décadas de 1880 y 1890: entre las salvadoreñas, destacaban las consagradas a la caridad y a la beneficencia, y casinos y clubes, todos espacios de sociabilidad de las jerarquías sociales urbanas; $;{ }^{34}$ entre las nicaragüenses, sobresalían las culturales y educativas; y entre las costarricenses, el predominio correspondía a sociedades de carácter artesano-obrero.

${ }^{34}$ Para una comparación con las asociaciones francesas, véase: Maurice Agulhon, Historia vagabunda. Etnología y política en la Francia contemporánea (México 1994), pp. 17-53. 
CUADRO 3

Libros y FOLLETOS PUbliCAdos EN COSTA Rica (CR), NiCARAGUA (NIC) y El SALVADOR (ES) SEGÚN SU TEMÁTICA (1880-1899)

\begin{tabular}{lrrrrrrrrr}
\hline Temática & \multicolumn{3}{c}{ Oficiales } & \multicolumn{3}{c}{ Institucionales } & \multicolumn{3}{c}{ Particulares } \\
& CR & Nic & ES & CR & Nic & ES & CR & Nic & ES \\
\hline Agricultura & 15 & 1 & $\ldots$ & $\ldots$ & $\ldots$ & $\ldots$ & $\ldots$ & 3 & 1 \\
Antropología y & & & & & & & & & \\
sociología & 4 & 1 & 1 & $\ldots$ & $\ldots$ & $\ldots$ & 1 & $\ldots$ & 2 \\
Ciencias físicas & & & & & & & & & \\
y naturales & 28 & $\ldots$ & 10 & $\ldots$ & $\ldots$ & $\ldots$ & 5 & 2 & 13 \\
Derecho & 8 & 5 & 2 & 1 & $\ldots$ & 2 & 20 & 18 & 40 \\
Economía & 25 & 22 & 24 & 2 & 2 & 6 & 6 & 1 & 17 \\
Educación & 6 & 1 & 12 & $\ldots$ & 2 & 4 & 8 & $\ldots$ & 3 \\
Estatutos y prospectos & $\ldots$ & 1 & 7 & 5 & 15 & 35 & $\ldots$ & $\ldots$ & $\ldots$ \\
Filosofía y Filología & 5 & $\ldots$ & 2 & $\ldots$ & $\ldots$ & $\ldots$ & 12 & 3 & 5 \\
Historia y Geografía & 32 & 13 & 2 & $\ldots$ & $\ldots$ & $\ldots$ & 18 & 15 & 13 \\
Informes y memorias & 84 & 4 & 57 & 3 & 3 & 20 & $\ldots$ & $\ldots$ & $\ldots$ \\
Leyes y reglamentos & 16 & 107 & 99 & $\ldots$ & 4 & 27 & $\ldots$ & $\ldots$ & $\ldots$ \\
Literatura & 3 & 7 & 1 & $\ldots$ & $\ldots$ & 1 & 27 & 24 & 24 \\
Medicina & 2 & 2 & 6 & $\ldots$ & $\ldots$ & $\ldots$ & 4 & 1 & 41 \\
Milicia & 22 & 14 & 1 & $\ldots$ & $\ldots$ & $\ldots$ & 1 & 1 & 1 \\
Política & 21 & 49 & 20 & $\ldots$ & 7 & $\ldots$ & 38 & 35 & 54 \\
Religión & $\ldots$ & 1 & $\ldots$ & 6 & 6 & 1 & 16 & 5 & 9 \\
Otros & 28 & 8 & 3 & $\ldots$ & $\ldots$ & 3 & $\ldots$ & 5 & 8 \\
\hline Total & 299 & 236 & 247 & 17 & 39 & 99 & 156 & 113 & 231 \\
\hline
\end{tabular}

Fuente: García Villas, "Lista preliminar de la Bibliografía Salvadoreña" (nota 5); Luis Dobles Segreda, Índice bibliográfico de Costa Rica (nota 5); Latin American Bibliographic Foundation y Ministerio de Cultura de Nicaragua, Bibliografía nacional nicaragüense (nota 5).

La escasa organización popular en El Salvador es visible en que, a pesar de que su población urbana era 4,4 veces mayor que la de Costa Rica en 1892, el total de asociaciones de trabajadores (incluidas las cajas de ahorro) era 3,7 veces inferior al costarricense. ${ }^{35}$ La temprana y decidida formación de sociedades artesano-obreras contribuyó a

${ }^{35}$ El promedio se obtiene al dividir las 26 organizaciones y cajas de ahorro costarricenses entre las 7 salvadoreñas. 


\section{Cuadro 4 \\ ORGANIZACIONES NO ESTATALES Y ENTIDADES DESCENTRALIZADAS en Costa Rica, Nicaragua, y El Salvador (1880-1899) \\ DATOS FRAGMENTARIOS}

\begin{tabular}{lcccccc}
\hline \multirow{2}{*}{ Tipo de organización } & \multicolumn{2}{c}{ Costa Rica } & \multicolumn{2}{c}{ Nicaragua } & \multicolumn{2}{c}{ El Salvador } \\
& Total & $\%$ & Total & $\%$ & Total & $\%$ \\
\hline Clubes y casinos & 3 & 4,6 & 3 & 23,1 & 10 & 16,9 \\
Cultural & 4 & 6,2 & 3 & 23,1 & 8 & 13,6 \\
Caridad y beneficencia & 7 & 10,8 & $\ldots$ & $\ldots$ & 8 & 13,6 \\
Religiosa y moral & 2 & 3,1 & 1 & 7,7 & 5 & 8,5 \\
Cajas de ahorro & 3 & 4,6 & $\ldots$ & $\ldots$ & 5 & 8,5 \\
Profesional & 6 & 9,2 & 2 & 15,4 & 3 & 5,1 \\
Escuelas de adultos & 3 & 4,6 & $\ldots$ & $\ldots$ & 3 & 5,1 \\
Deportiva & 1 & 1,5 & $\ldots$ & $\ldots$ & 1 & 1,6 \\
Artesanos y trabajadores* & 23 & 35,4 & 1 & 7,7 & 2 & 3,4 \\
Agricultores & 1 & 1,5 & 1 & 7,7 & $\ldots$ & $\ldots$ \\
Hospitales, asilos y Cruz Roja & 12 & 18,5 & 2 & 15,4 & 14 & 23,7 \\
\hline Total & 65 & 100 & 13 & 100 & 59 & 100 \\
\hline
\end{tabular}

Incluye una organización fundada en 1872 en El Salvador y otra establecida en 1874 en Costa Rica. Fuente: García Villas, "Lista preliminar de la Bibliografía Salvadoreña" (nota 5); Latin American Bibliographic Foundation y Ministerio de Cultura de Nicaragua, Bibliografía nacional nicaragüense (nota 5); International Bureau of American Republics, Handbook of Salvador (nota 9), pp. 31-32; Carlos Luis Fallas Monge, El movimiento obrero en Costa Rica (1830-1902) (San José 1983); y Oficial, Colección de leyes y decretos (San José 1880-1899).

ampliar y diversificar la esfera pública en este último país, y la cultura impresa también: en efecto, entre 1883 y 1895, esas agrupaciones publicaron, por lo menos, seis periódicos, todos editados en San José, uno quincenal y cinco semanales, uno de los cuales tenía un tiraje de 1.000 ejemplares en 1889. Esta experiencia contrasta con la nicaragüense y la salvadoreña, cuya prensa de este tipo, se limitó a La Aurora (1883) en el primer país, y a El Obrero (1873) y al Telégrafo del Salvador (1889) en el segundo. ${ }^{36}$

${ }^{36}$ Víctor Hugo Acuña, "Clases subalternas y movimientos sociales en Centroamérica (1870-1930)": Víctor Hugo Acuña (ed.), Historia general de Centroamérica. Las repúblicas agroexportadoras (Madrid 1993), pp. 255-323, aquí: p. 275; Oliva, Artesanos y obreros costarricenses (nota 24), pp. 101-102; López Vallecillos, El periodismo en El Salvador (nota 14), pp. 301-302. 


\section{TESIS, LITERATURA Y OTROS TÓPICOS}

Las publicaciones de carácter particular en El Salvador superaron proporcionalmente a las de Costa Rica y Nicaragua (un 40 contra un 33,1 y un 29,1 por ciento). La base de esa diferencia fueron las tesis, las cuales, en el primer país, representaron un 18,7 del 40 por ciento indicado; en el segundo, solo un 0,2 del 33,1 por ciento especificado; y en el tercero un 0,7 del 29,1 por ciento indicado. La mayoría de esas disertaciones salvadoreñas versaban sobre derecho y medicina, un dato que explica la elevada concentración de textos en esos campos que se observa en el Cuadro 3. Los tesiarios costarricenses (un caso) y nicaragüenses (tres casos) rara vez publicaron su trabajo de graduación como libro o folleto. ${ }^{37}$

¿Fue la ausencia de revistas especializadas lo que determinó que en El Salvador las tesis fueran publicadas como folletos independientes? La evidencia disponible, aunque limitada, se orienta en esa dirección: en Costa Rica, la revista de derecho, El Foro, y la Gaceta Médica, empezaron a circular en 1882 y en 1896, respectivamente; en contraste, la Revista Judicial salvadoreña se fundó en 1892, diez años después que la costarricense. Lo inverso ocurrió con la Gaceta Médica, establecida en San Salvador en 1881, pero su vida fue efímera, lo mismo que la de sus sucesoras, La Clínica (1892), órgano del Hospital General de la capital, y la Revista Médico-Farmacéutica (1893), vocero de la sociedad estudiantil homónima.

La creación literaria, a juzgar por los datos del Cuadro 3, fue más importante en Nicaragua (21,2 por ciento) y Costa Rica (17,3 por ciento) que en El Salvador (10,4 por ciento), una diferencia que persiste aun si se consideran las cifras absolutas ( 31 y 30 contra 26 textos). La desventaja salvadoreña en esta área conviene resaltarla porque los datos precedentes exigen considerar, con más detalle y cuidado, la imagen de una dinámica producción en el campo de las "bellas letras", que ofrece el artículo de Burns. ${ }^{38}$ La literatura, pieza clave en la in-

${ }^{37}$ En Costa Rica, a diferencia de El Salvador, no existía una escuela de medicina. Sobre la educación universitaria costarricense durante el siglo XIX, véase: Paulino González, La Universidad de Santo Tomás (San José 1990).

${ }^{38}$ Burns, "The Intellectual Infrastructure" (nota 1), pp. 67-76. Burns indicó que se imprimieron muy pocos libros, aunque no dio estadísticas al respecto, y señaló que la mayor parte de la producción literaria fue, en consecuencia, publicada en periódicos y revistas, cuyas limitaciones ya fueron analizadas. 
vención de las nación, ${ }^{39}$ fue solo una práctica cultural esporádica en la "infraestructura intelectual" que tuvo por asiento principal el casco urbano de San Salvador.

El Estado costarricense, en contraste con el nicaragüense y el salvadoreño, fue un patrocinador sistemático de textos agrícolas, científicos, históricos, geográficos y militares. El énfasis en tales áreas se vinculaba con el interés oficial por determinar las especificidades de Costa Rica en los mundos natural y social, un esfuerzo cuyo trasfondo nacionalista es evidente. Los textos publicados, sin embargo, no consistían únicamente en obras especializadas, sino que incluían cartillas, cuyo fin era difundir entre el conjunto de la población los valores del patriotismo, la ciencia, la disciplina, el aseo y otros asociados con la ideología del progreso. La alfabetización creciente fue la base de esta campaña dirigida a "civilizar" las culturas populares de la ciudad y el campo (las cuales se apropiaron, en sus propios términos, de ese programa, como se verá más adelante). ${ }^{40}$

La fundación en San José del Museo Nacional en 1887 y del Instituto Físico Geográfico en 1888 fue un doble evento institucional que estimuló la investigación y la publicación en las áreas de la geografía y las ciencias naturales. Las revistas asociadas con tales entidades facilitaron la divulgación de los conocimientos adquiridos por un activo círculo de científicos locales y extranjeros ${ }^{41}$ y varios de los artículos que vieron la luz en sus páginas, luego fueron impresos como folletos, con el propósito de facilitar su difusión o de utilizarlos como textos escolares. ${ }^{42}$ La experiencia de El Salvador fue, de nuevo, distinta: el Museo Nacional se creó en 1902, y Anales del Museo Nacional solo empezó a circular en $1903 .{ }^{43}$

39 Doris Sommer, Foundational Fictions: The National Romances of Latin America (Berkely 1991). Para el caso específico de Costa Rica, véase: Álvaro Quesada, Uno y los otros. Identidad y literatura en Costa Rica 1890-1940 (San José 1998), pp. 17-54.

${ }^{40}$ La dimensión escolar del conflicto entre el proyecto liberal y las comunidades populares se examina en: Steven Palmer/Gladys Rojas, "Educating Señorita: Teacher Training, Social Mobility, and the Birth of Costa Rican Feminism, 1885-1925": Hispanic American Historical Review 78, 1 (Durham 1998), pp. 45-82, aquí: pp. 59-60.

${ }^{41}$ Marshall C. Eakin, "The Origins of Modern Science in Costa Rica: The Instituto Físico-Geográfico Nacional, 1887-1904": Latin American Research Review 34, 1 (Albuquerque 1999), pp. 123-150.

${ }_{42}$ Molina, El que quiera divertirse (nota 24), pp. 136-141.

${ }^{43}$ López Vallecillos, El periodismo en El Salvador (nota 14), pp. 224-225. 
El considerable número de obras militares, patrocinadas por el Estado, es un apropiado recordatorio de que en Costa Rica, tan asociada con los gobiernos civiles, el Poder Ejecutivo estuvo dominado por los generales entre 1870 y $1889 .{ }^{44}$ El elevado porcentaje de ese tipo de textos es, a la vez, un indicador de los altos niveles de alfabetización que tenían los oficiales y soldados costarricenses: según el censo de 1892 , entre 50 y 60 por ciento de los varones en edad de cumplir con el servicio de las armas sabía por lo menos leer. ${ }^{45}$ La proporción de salvadoreños de similar condición, a juzgar por la evidencia fragmentaria disponible, fue mucho más baja: entre 30 y 40 por ciento. ${ }^{46}$

La escasez de publicaciones militares en El Salvador podría indicar, simplemente, que en dicho país, en vez de producirlas, las importaban; pero cabe también otra explicación: ¿qué sentido tenía imprimir textos de esa índole cuando la mayoría de los que integraban las fuerzas armadas (la tropa y verosímilmente la baja oficialidad) no sabía siquiera leer? Este razonamiento obliga, además, a cuestionar la hipótesis de que, dadas las limitaciones del sistema educativo, fue el ejército salvadoreño el que asumió la tarea de moralizar a los sectores populares y de construir una identidad nacional. ${ }^{47}$ ¿Cómo pudo cumplir con esas funciones una institución en la cual el analfabetismo era tan elevado?

La limitada alfabetización popular se aprecia, desde otra perspectiva, al considerar la poca importancia de los libros y folletos religiosos en Nicaragua y El Salvador, cuya experiencia en esta área contrasta, de nuevo, con la de Costa Rica. La alfabetización creciente en este último país, sobre todo en el campo, consolidó un mercado para toda una serie de obritas devotas, que incluían breviarios, catecismos, no-

${ }^{44}$ El período señalado es analizado en: Orlando Salazar, El apogeo de la república liberal en Costa Rica 1870-1914 (San José 1990).

45 El 45,2 por ciento de la poblacion de diez años y más, en 1892, sabía por lo menos leer y, si se pudiera discriminar el analfabetismo femenino (que, como mínimo, superaba al masculino en un 10 por ciento), la proporción de los varones alfabetas de 20 años y más se ubicaría en el orden indicado. Censo general de la República de Costa Rica (nota 11), pp. cviii-cix; Censo de población de Costa Rica (nota 20), pp, 267 y 269.

${ }^{46}$ El porcentaje se calculó con base en los 185.000 alfabetas que supuestamente existían en El Salvador en 1887, y la muy probable sobrevaloración de esa cifra, se controló con los datos del censo de 1950. Véase: López Bernal, "El proyecto liberal de nación" (nota 23), p. 67; Lungo Uclés/Baires, "Población y economía" (nota 9), p. 137; Segundo censo de población (nota 20), p. 298.

${ }^{47}$ Patricia Alvarenga, Cultura y ética de la violencia. El Salvador 1880-1932 (San José 1996), pp. 144-156. 
venas, santorales y otras por el estilo. El consumo de esos textos, que databa de la época colonial, perduró y se extendió en el siglo XIX, un proceso que evidencia cómo las familias campesinas y artesanas, que accedieron a la instrucción pública promovida por los liberales, utilizaron sus nuevas destrezas culturales con fines muy distintos, sin duda, de los que tenía la intelectualidad positivista.

La distancia que separaba a Costa Rica de El Salvador, en cuanto a la circulación de obras piadosas, se vislumbra mejor al comparar la librería de Emilio Villacorta, la cual fue rematada en el San Salvador de 1923, con la de "El Álbum", un establecimiento que operaba en el San José de 1858. La oferta de textos devotos en este último era, en cuanto a número de títulos (126 contra 19) y ejemplares (206 contra 130) disponibles, mucho mayor que la del local salvadoreño de 65 años después. ${ }^{48}$ La cultura impresa costarricense, desde temprano, se caracterizó por una dinámica que integraba las preferencias de los lectores populares, una tendencia facilitada por la alfabetización creciente de la población rural y urbana.

La descripción de las librerías josefinas que efectuó Alberto Masferrer a finales del siglo XIX, es de por sí elocuente sobre la integración indicada; después de una estadía en Costa Rica, advirtió:

“... no hay libro bueno que no se encuentre, ni lujosa edición que falte para recreo de la vista y el espíritu. Todo Hugo, Rabelais, Taine, Macaulay, de Lisle, Carlyle, Goethe y Heine; los griegos en ediciones económicas francesas; el arsenal completo de Schopenhauer, los clásicos ingleses, la biblioteca entera de Rivadeneira. La masa, claro está, se deleita con el admirable Ponson du Terrail y con el exquisito Montepin; mas los escogidos leen de veras, y a la mano tienen las grandes producciones del ingenio humano." 49

La amplia brecha entre las jerarquías sociales y el mundo popular en El Salvador de fines del siglo XIX encontró una de sus mejores expresiones en la Biblioteca Nacional, fundada en 1870, y cuya base fue la colección personal del cardenal Mambrushini, exbibliotecario del Vaticano. Las existencias de esta institución ascendían, en 1887, a 6.801

48 Iván Molina, "La cultura a remate. Documentos para la historia cultural de El Salvador. La librería de Villacorta (1923)": Revista de Filosofía XXXII, 78-79 (San José 1994), pp. 235-245. El adverso desempeño económico de la librería, que condujo a su remate, pudo afectar el inventario que sirvió de base para la comparación expuesta.

49 Alberto Masferrer, Hombres, ciudades, paisajes (San Salvador 1949), tomo II, p. 298. 
volúmenes, la mayoría escritos en latín e italiano, ya que únicamente un 20,3 por ciento se encontraba en español. La proporción de obras en este último idioma en las contrapartes nicaragüense y costarricense ascendía, en contraste, a 44,1 y 45,5 por ciento de los totales respectivos; y la de Costa Rica, en particular, con sus revistas ilustradas y novelas de aventuras, fue un centro de atracción de lectores de muy variado origen social. ${ }^{50}$

\section{CULTURA IMPRESA E IDENTIDAD NACIONAL}

La "invención" de la nación, y de las "tradiciones" indispensables para darle a tal proceso cobertura espacial y profundidad cronológica, suelen estar asociadas con una producción creciente de textos de carácter geográfico e histórico. ${ }^{51}$ Los libros y folletos publicados en El Salvador sobre estos temas, entre 1880 y 1899 , fueron muy pocos: 15 títulos contra 28 y 50 que fueron impresos en Nicaragua y Costa Rica; y a diferencia de los casos nicaragüense (13 de 28) y costarricense (32 de 50), el Estado salvadoreño únicamente patrocinó 2 de las 15 obras que circularon entonces. La inmadurez del nacionalismo oficial en ese país se evidencia en el desinterés por esos tópicos claves. ${ }^{52}$

El Estado empezó a impulsar la nacionalización del pasado de El Salvador en las décadas de 1910 y 1920. Los intelectuales de esa época, al tiempo que rechazaban a las comunidades aborígenes existentes, a las que consideraban como obstáculos para el "progreso", idealizaron los tiempos prehispánicos y mitificaron a Atlacatl el joven, al cual se esforzaron por convertir en un héroe nacional..$^{53} \mathrm{El}$ contraste con los

${ }^{50}$ Iván Molina, "Mercancías culturales. Libros europeos en las bibliotecas nacionales de El Salvador, Nicaragua y Costa Rica a fines del siglo XIX": Michael Zeuske/ Ulrike Schmieder (eds.), Regiones e identidades en Europa y América Latina (Colonia 1998), pp. 255-277.

${ }^{51}$ Sobre esta problemática, véase: Anderson, Imagined Communities (nota 15); Eric J. Hobsbawm, Nations and Nationalism Since 1780. Programme, Myth, Reality (Cambridge 1990); ídem/Terence Ranger (eds.), The Invention of Tradition (Cambridge 1983).

52 Según Burns, entre los textos escolares predominaban los geográficos, históricos y cívicos, una conclusión que no es apoyada por el análisis estadístico de las obras impresas en El Salvador entre 1880 y 1899. Burns, "The Intellectual Infrastructure" (nota 1), p. 76.

${ }_{53}$ López Bernal, "El proyecto liberal de nación” (nota 23), pp. 79-84 y 154-171. 
años 1880-1899 no podía ser mayor: ni uno solo de los libros y folletos localizados para ese período tiene en su título la palabra indio o indígena. El racismo intelectual de fines del siglo XIX se prolongó, en el $\mathrm{XX}$, bajo la máscara del folclore que, al celebrar a los guerreros anteriores a la conquista española, permitía destacar la supuesta degeneración de sus descendientes, quienes en 1901 representaban, según cifras oficiales, el 33 por ciento de toda la población salvadoreña. ${ }^{54}$

Las contradicciones del proceso de "invención" de la nación en El Salvador son más visibles al considerar los casos de Nicaragua y Costa Rica. Los intelectuales nicaragüenses, al tiempo que definían a su país como étnicamente mestizo, ${ }^{55}$ asociaron su identidad nacional con un destino cosmopolita que constituía la quintaesencia del "progreso": el canal interoceánico. ${ }^{56}$ Los costarricenses fueron, en cierto sentido, más lejos, ya que conceptualizaron su sociedad como una que era "blanca", igualitaria, casi europea y excepcional en América Latina. El pasado indígena, en tal contexto, se convirtió en otro objeto más de exhibición museográfica al finalizar el siglo XIX. ${ }^{57}$

Las experiencias nicaragüense y costarricense también difirieron de la salvadoreña en cuanto a la "invención" de la figura que simbolizaría el sacrificio por la patria. El culturalmente distante Atlacatl el joven contrasta agudamente con dos personajes "republicanos", cuyas hazañas databan de la guerra de 1856-1857, que enfrentó a los ejércitos del istmo contra las fuerzas de William Walker. ${ }^{58} \mathrm{El}$ general granadino

${ }^{54}$ Aldo A. Lauria-Santiago, An Agrarian Republic. Commercial Agriculture and the Politics of Peasant Communities in El Salvador, 1823-1914 (Pittsburgh 1999), pp. $59-60$.

55 La población indígena en la Nicaragua de 1920 ascendía, según Gould, a un 15 por ciento como mínimo. Jeffrey L. Gould, El mito de "la Nicaragua mestiza" y la resistencia indígena, 1880-1980 (San José 1997), pp. 233-236. Para la versión inglesa de la problemática discutida en este libro, véase: ídem, To Die in This Way. Nicaraguan Indians and the Myth of Mestizaje, 1880-1965 (Durham 1998).

${ }^{56}$ Frances Kinloch, "El canal interoceánico en el imaginario nacional. Nicaragua, siglo XIX": Taller de Historia 6 (Managua 1994), pp. 39-55. Miguel Ángel Herrera, Bongos, bogas, vapores y marinos. Historia de los marineros del río San Juan (Managua 2000).

57 Steven Palmer, "Racismo intelectual en Costa Rica y Guatemala, 1870-1920": Mesoamérica 17, 31 (South Woodstock, USA/La Antigua, Guatemala 1996), pp. 99-121; Ronny Viales, "El Museo Nacional de Costa Rica y los albores del discurso nacional costarricense (1887-1900)": Vínculos 21, 1-2 (San José 1997), pp. 99-123.

58 Burns, Patriarch and Folk (nota 18). Para una crónica de la guerra de 1856-1857 desde la perspectiva costarricense, véase: Rafael Obregón Loría, Costa Rica y la guerra contra los filibusteros (Alajuela 1991). 
José Dolores Estrada, que derrotó a los "filibusteros" en la batalla de San Jacinto (el 14 de septiembre de 1856) fue convertido, durante el largo dominio del Poder Ejecutivo por los conservadores (18571893), en el héroe nacional de Nicaragua..$^{59}$

La figura de Estrada, invocada en función de una identidad nacional que debería estar por encima de los intereses localistas de las jerarquías sociales de León y Granada, difiere de la de Juan Santamaría, un soldado costarricense, de origen mulato, quien murió durante la batalla de Rivas (el 11 de abril de 1856). Los intelectuales liberales de San José, tras blanquearlo debidamente, lo convirtieron en el héroe nacional en las décadas de 1880 y 1890 . El modelo a imitar que le ofrecieron a campesinos, artesanos y obreros era uno de los mejores que podían imaginar: un personaje republicano, de indudable extracción popular y fallecido en el extranjero para defender el orden existente en Costa Rica. ${ }^{60}$

El caso de Santamaría es otro ejemplo apropiado de la integración de lo popular en el proceso de "invención" de la nación en Costa Rica. Los políticos e intelectuales de ese país construyeron un proyecto social y cultural orientado simultáneamente a "civilizar" a los sectores populares y a integrarlos en la sociedad nacional. La cultura impresa fue un componente básico de esta dinámica, ya que la "nacionalización" y "civilización" de las familias artesanas, obreras y campesinas suponía, ante todo, alfabetizarlas, y a la vez, facilitar que se apropiaran, mediante folletos, revistas y periódicos, de toda una serie de valores seculares y positivistas. El amplio consumo de textos piadosos y de novelas de aventuras y del corazón patentiza uno de los límites de tal proceso.

Los círculos de políticos e intelectuales de El Salvador carecieron de un proyecto similar a finales del siglo XIX: "civilizar" y "nacionalizar" a los grupos populares, en su mayoría analfabetas, e indígenas en una proporción significativa, no era parte de su agenda. La cultura impresa que se configuró en tales circunstancias fue claramente folletinesca, dominada por las tesis y los textos oficiales e institucionales

${ }^{59}$ Fumero, "De la iniciativa individual" (nota 19), pp. 13-41.

60 Steven Palmer, "Sociedad anónima, cultura oficial: inventando la nación en Costa Rica (1848-1900)": Iván Molina/Steven Palmer (eds.), Héroes al gusto y libros de moda. Sociedad y cambio cultural en Costa Rica (1750-1900) (San José 1992), pp. 169-205. 
de carácter formal (memorias, reglamentos, estatutos y otros por el estilo). La producción literaria, histórica y geográfica fue escasa y esporádica, una tendencia acorde con el tardío y errático proceso de "invención" de la nación. Este último constituye, a su vez, un indicador de la brecha que separaba a la intelectualidad salvadoreña del conjunto de su sociedad, lo que confirma, desde otra perspectiva, una de las conclusiones principales de Burns. ${ }^{61}$

\section{CONCLUSIÓN}

El artículo de Burns fue, sin duda, un estudio pionero que, al esforzarse por superar el enfoque tradicional de la historia de las ideas, ${ }^{62}$ se aproximó a un sofisticado análisis social de los círculos intelectuales salvadoreños del período posterior a 1870 . El valor de este trabajo, más allá de sus aportes concretos sobre el tema específico de que trata, consiste en que propuso todo un nuevo programa de investigación en el campo cultural: entre otros, la influencia europea en la cultura urbana del istmo, la creación de organizaciones e instituciones vinculadas con la ciencia y las "bellas letras", la producción impresa y la brecha creciente entre las jerarquías sociales de las ciudades y el grueso de la población, en especial la del agro.

La limitada valoración del estudio de Burns por los centroamericanistas de las décadas de 1980 y 1990 quizá se explica por el énfasis de estos últimos en los temas agrarios, lo que supuso un lamentable descuido de otras dimensiones de la vida social, entre las cuales figuran la cultura urbana y, por supuesto, los círculos intelectuales. Los dos mejores libros publicados en años recientes sobre El Salvador rural de finales del siglo XIX ${ }^{63}$ ni siquiera citan el artículo de 1985. Este es un indicador de esas frecuentes desconexiones académicas en cuyo curso la dinámica de la investigación conduce a sus practicantes a una especialización creciente a costa de la visión de conjunto.

${ }^{61}$ Burns, "The Intellectual Infrastructure" (nota 1), pp. 81-82.

62 Véase al respecto: Robert Darnton, The Kiss of Lamourette. Reflections in Cultural History (New York 1990), pp. 191-252.

${ }_{63}$ Lauria-Santiago, An Agrarian Republic (nota 54); Alvarenga, Cultura y ética de la violencia (nota 47$)$. 
La recuperación, a más de tres lustros de distancia, de la problemática avanzada por Burns en 1985, exige identificar las limitaciones de su propuesta, entre las cuales cabe destacar una temática, una empírica y una metodológica. La primera se relaciona con que, aunque se acercó a dos tópicos que experimentarían a futuro una expansión vertiginosa en los estudios sobre América Latina, él no los explicitó: la "invención" de la nación y la configuración de una esfera pública. ${ }^{64} \mathrm{El}$ concepto de "infraestructura intelectual", un eco de las investigación previa del autor en el campo de la historia económica, fue a la vez operativo y limitante: aunque le permitió darle un tratamiento integrado a la información diversa de que disponía, no le facilitó una apropiada profundización teórica.

La dificultad precedente fue agravada porque Burns contaba con datos tan variados como fragmentarios: descripciones de viajeros, citas de periódicos, estadísticas dispersas; y sin duda, logró mucho al analizar una evidencia de esta índole. El resultado final, sin embargo, fue bastante "impresionista", y las insuficiencias del material empírico no fueron compensadas a nivel metodológico, ya que fue precisamente la falta de una perspectiva comparativa la que le impidió contextualizar adecuadamente la experiencia salvadoreña. Los umbrales de esta última se visualizan claramente al confrontar su cultura impresa con la que se configuró en Nicaragua y, especialmente, en Costa Rica entre 1880 y 1899.

La "infraestructura intelectual" de El Salvador, vista a la luz de esa comparación, no se presenta como "sólida", sino como frágil y extremadamente limitada. La creciente alfabetización popular en Costa Rica a la vez que actualizó el marco cultural de las relaciones sociales, contribuyó a que la esfera pública se configurara como un espacio social y culturalmente compartido y disputado por los distintos actores colectivos (aunque en condiciones y proporciones desiguales). El efecto más visible de lo anterior fue que las reivindicaciones populares lograron un acceso sistemático a la cultura impresa, un proceso en cuyo curso la "cuestión social" se convirtió en uno de los ejes del de-

${ }^{64}$ Entre otros, véase: Sommer, Foundational Fictions (nota 39). Steven Palmer, "A Liberal Discipline: Inventing Nations in Costa Rica and Guatemala" (PhD Thesis, Columbia University, 1990). Hilda Sabato, "Citizenship, Political Participation and the Formation of the Public Sphere in Buenos Aires, 1850s-1890s": Past and Present 136 (Oxford 1992), pp. 139-163. 
bate nacional, de la competencia electoral entre los partidos y de la acción del Estado.

La cultura impresa salvadoreña, en ciertos aspectos, estuvo más cercana a la de Nicaragua que a la de Costa Rica; pero incluso en el caso nicaragüense, la tipografía estatal jugó un papel preponderante en el tiraje de obras, y el Estado patrocinó más sistemáticamente la publicación de textos claves, en términos de la invención de la nación. El Salvador, donde la brecha entre las jerarquías sociales y el grueso de la población no fue compensada por el sistema educativo, vivió una experiencia muy diferente de la costarricense. El universo letrado en particular, y la esfera pública en general, se constituyeron como espacios social y culturalmente exclusivos y excluyentes: de cara a Europa $\mathrm{y}$ de espaldas a un mundo popular (y sobre todo rural) en el que los indígenas tenían un peso decisivo.

La "república de las letras" de El Salvador, con su énfasis en las tesis universitarias, los estatutos de los clubes y casinos y otros textos similares, se constituyó en función no de una identidad nacional, sino de una de clase: la de los sectores medios y acaudalados del mundo urbano. La "infraestructura intelectual" analizada por Burns evidenciaría su perfil más ominoso a inicios del siglo XX cuando, incapaz de apropiarse de los discursos favorables a la reforma social de esa época, y en particular del "mínimum vital" de Masferrer, ${ }^{65}$ justificaría la masacre de 1932.

${ }^{65}$ Karen Racine, "Alberto Masferrer and the Vital Minimum: The Life and Thought of a Salvadoran Journalist, 1868-1932”: The Americas 54, 2 (Washington 1997), pp. 209-237; E. Bradford Burns, "Modernization of Underdevelopment: El Salvador 1858-1931": Journal of Developing Areas 3, 18 (Macomb 1984), pp. 309-310. 
